the chitin itself. In this respect the hawk moth cuticle is similar; by extracting 'chitin' residues (after removing the very soluble protein I) with a more powerfully disrupting reagent it was possible to obtain a protein fraction II which contained amino sugar and was much richer in carbohydrate and sulphur than the whole cuticle. The chitin residue after this treatment had slightly lower than the calculated nitrogen content and contained no further protein, but still contained traces of sulphur and non-amino carbohydrate. The nature of the sulphur, which is combined, has not been definitely established.

The evidence supports the view that the carbohydrate and sulphur (possibly ethereal sulphate sulphur) are concerned in linking the protein to the chitin, which has, until now, been regarded as a neutral polysaccharide. It may now be tentatively suggested that the protein and chitin are linked in a similar way to that in the known mucoproteins (see Meyer ${ }^{7}$ ). It is interesting that Dr. K. M. Rudall (private communication), working on the same problem using $\mathrm{X}$-ray analysis, now has evidence for a definite but weak chemical link between protein and chitin in the larval cuticle of Sarcophaga falculata.

This work suggests a chemical similarity between the chitin-protein complex of the insect cuticle and the known mucopolysaccharide-protein aggregates. It throws light on the problem of chitin formation, and shows that the cuticle is composed of components of the nature postulated from the properties of the cuticle now under investigation by Hurst $^{8}$ in his studies of insecticidal action.

This work was made possible by a grant from the Agricultural Research Council and has been carried out in the Biochemical Laboratory and the Biological Field Station of the Imperial College of Science and Technology. I am greatly indebted to Prof. A. C. Chibnall and to Prof. J. W. Munro for their continued interest and encouragement. I must also thank Drs. K. M. Rudall and G. Fraenkel for their interest and help.

Biological Field Station,

(Imperial College of Science and Technology), Slough, Bucks.

Dec. 20.

${ }^{2}$ Odier, Mem. Soc. Hist. Nat. (Paris), 1, 29 (1823).

${ }^{2}$ Wigglesworth, Quart. J. Micro. Sci., 76, 269 (1933-34).

${ }^{3}$ Pryor, Proc. Roy. Soc., B, 123, 393 (1940).

- Fraenkel and Rudall, Proc. Roy. Soc., B, 129, 1 (1940).

${ }^{5}$ Scott, Amer. Dyestuff8 Reporter, 28, 501 (1939).

${ }^{6}$ Alders, Biochem. Z., 183, 446 (1927).

'Meyer, Cold Spring Harbour Symp., 6, 91 (1938).

S Hurst, NATURE, 145, 462 (1940); and private communication.

\section{Permeability of Insect Cuticle}

IN a recent communication ${ }^{1}$ Hurst has described a series of important observations which go far to explain the action of non-toxic paraffins in facilitating the penetration of insecticides through the cuticle of insects. He provides evidence that "apolar substances of low dielectric constant" greatly increase the permeability of the outer lipoid layer of the cuticle.

I have recently obtained confirmation of this view in the following way. A small insect, such as a flea or louse, is immersed in oil and examined under the microscope. Within a few minutes if xylol is used, within half an hour or so if medicinal paraffin or olive oil is used, minute droplets of water begin to appear all over the cuticle; often most markedly on the hardest parts, such as the claws of the louse. Presumably polar substances of some kind crowd into the oil-water interface as the lipoid layer dissolves, and thus draw out the water droplets.

If such an insect is immersed in a mixture of ethyl alcohol and kerosene as described by Hurst, and watched under the microscope, the droplets swell up and separate with such violence that the insect seems to be effervescing. This, of course, is because in the presence of traces of water the alcohol separates from the paraffin. The same thing is seen, among other mixtures, in kerosene and acetone, carbon disulphide and ethyl alcohol, medicinal paraffin and butyl alcohol and, less violently, in medicinal paraffin and pyridine or dodecyl thiocyanate and pyridine. In benzene and ethyl alcohol diffusion currents appear over the cuticle but few droplets separate.

Besides substantiating Hurst's valuable discovery, these observations stress the importance of the partition coefficient of a substance between oil and water in determining the rate at which it will leave the oily base of a contact insecticide and enter the tissues of an insect. This simple conception may prove helpful for the rational selection of active principles and solvents in the preparation of contact insecticides.

\section{B. WiggLESWORTH.}

London School of Hygiene

and Tropical Medicine,

Keppel Street,

London, W.C.1.

Dec. 19.

${ }^{1}$ Hurst, H., NATURE, 145, 462 (1940).

\section{Sex-Ratio in Urosalpinx cinerea, the American Oyster Drill}

IN the course of preliminary studies of the biology of the introduced American oyster drill, Urosalpinx cinerea, it was noticed that among drills kept in a tank at Conway a very large proportion of the medium-sized and large individuals deposited eggcapsules. This led to an investigation of the sex-ratio in this molluse, the results of which are described briefly below. The sex of Urosalpinx is easily determined macroscopically, for the male has a com. paratively large curved penis lying behind and slightly to the right of the head; in addition the gonad of the female is yellow or orange, while that of the male is whitish. Although Urosalpinx has been closely studied in the United States ${ }^{1,2}$, no information is available concerning the sex-ratio.

Sex has been determined in a total of 1,946 drills belonging to sixteen samples dredged from the oyster beds in the Rivers Blackwater, Colne, Roach and Crouch. Of this total, 1,381 were females and 565 males, that is, females predominated to the extent of 71 per cent. In addition to this general preponderance of females there are also marked variations in the proportions of the two sexes in drills of different sizes. During the spring when the drills are spawning, there are about equal numbers of males and females among those with shells $2 \cdot 3 \mathrm{~cm}$. or less 